\title{
SOBRE LIBERTINOS Y LIBERTINAJE: GIULIO CESARE VANINI, UN DESCONOCIDO «PRÍNCIPE DE LOS LIBERTINOS»
}

\author{
Marcial CABALLERO
}

\begin{abstract}
«Seguire la storia del movimento libertino è seguire lo scorrere di un fiume carsico che, sgorgando in superficie nell'età di Pomponio Leto, di Pomponazzi, di Machiavelli, si inabissa nella profondità della terra al tempo della Riforma, del Concilio di Trento, delle guerre di religione, per riemergere alla luce del sole con Spinoza e Bayle, disperdendo poi le sue acque e confluendo nel grande fiume dell'Illuminismo".
\end{abstract}

(S. BERTELLI, Il libertinismo in Europa ${ }^{1}$ )

Diríase que el capítulo sobre los libertinos constituye una página en blanco de la historiografía en nuestros país. Nuestra peculiar forma de acceder a la modernidad de la mano de un Estado que se construye sobre la eliminación previa de la disidencia religiosa y que luego se convierte en campeón de la Contrarreforma, nos daría la clave fundamental de esta ausencia. Las guerras de religión (medio siglo ocupan en Francia hasta el Edicto de Nantes en 1598) han sido el suelo podrido en donde empezaron a crecer las semillas de una corriente de pensamiento, que bebe en las fuentes de la filosofía del Renacimiento menos asimilables para la ortodoxia católica, vinculándose directamente a ese proceso de secularización que constituye un argumento mayor de la cultura moderna y que sólo por una mala aproximación cabe referir como a su único origen a la Ilustración dieciochesca. Reducido a «libertinage des moeurs", un término que sólo corresponde a los libertinos del XVIII,

1 AA.VV., Il libertinismo in Europa, bajo la direc. de S. BERTELLI, Milán-Nápoles, 1980, p. 3. 
se desconocen las raices de esta corriente que en Europa se asocia a las primeras formas de disidencia o "libre pensamiento» y que encontró ya un primer significativo y polémico uso en el duro combate que enfrentó a protestantes y católicos, tras la violenta sacudida de la Reforma. Si Calvino utilizó por primera vez la palabra "libertin" contra las "desviaciones" que se producían en sus propias filas en su Brieve Instruction pour armer tous bons fidèles contre les erreurs de la secte commune des Anabaptistes (1544) ${ }^{2}$, los protestantes no tardarán en ser calificados de "libertinos" por los apologistas de la Contrarreforma que -como ha señalado G. Spini- a finales del s. XVI, defendían cómo

«...tra l'heresia riformata e l'ateismo vi era una identità sostanziale e che i corifei della Riforma erano degli impostori, pieni di ogni nefandeza specie in materia sessuale, i quali si erano serviti della religione per giustificare la propia licenza morale e la propia ribellione ad ogni autorità) ${ }^{3}$.

Convertido en arma arrojadiza de descalificación y de combate, el término presenta rasgos imprecisos hasta muy posteriormente. Como ha escrito R. Pintard, en su obra esencial: Le libertinage erudit dans la première moitiè du $X V I I^{e}$ siècle, en relación con este período,

«...est 'libertin' tout ce qui marque excès de 'liberté' en matière de morale et de religion, par rapport à ce que dogmes, traditions, convenances et pouvoir politique définissent ou préconisent" ${ }^{4}$.

Pero si se prescinde de esa carga polémica y de esa ambigüedad, y a medida que se aleja de su primera matriz religiosa, con el término «libertino" y más concretamente «libertinage erudito», nos estamos refiriendo, en el campo de la historia de las ideas, a un movimiento de intelectuales (clérigos eruditos, médicos, escritores, filósofos) que, tras la crisis social provocada por las guerras de religión en Francia, abren la vía a una forma de libre pensamiento que de manera más o menos abierta (frecuentemente el lenguaje utilizado es un lenguaje cifrado por la fuerte presión de la censura) se opone a la ortodoxia domi-

2 Cfr. J. C. MARGOLIN, Reflexions sur l'emploi du terme "libertin" au XVIe siècle, in Aspects du libertinisme au XVIe siècle. Actes du colloque international de Sommières, Paris, 1974, pp. $1-33$.

3 G. SPINI, «Ritrato del protestante come libertino", in Ricerche su litteratura libertina e letteratura clandestina nel Seicento, Florencia, 1981, p. 177.

4 Cfr. R. PINTARD, Le libertinage érudit dans la première moitié du XVIT siècle, Genève-Paris, 1983, p. XIV. 
nante y a las expresiones de credulidad y superstición popular, apoyándose en el patrimonio filosófico y cultural de la antigüedad pagana redescubierta por la cultura del Renacimiento y en manifestaciones propias de esta misma cultura renacentista.

Una serie de constantes aparecen como característica general de la corriente libertina, que T. Gregory ha resumido como sigue:

"...es importante la presencia de determinados autores antiguos y modernos, considerados como "maestros" e inspiradores de la cultura libertina cuya fuerte componente erudita se configura en el preciso empeño de recuperar textos y temas olvidados o marginados, instrumento necesario en la polémica contra la escala de valores dominantes, a la hora de delinear el inventario de los "errores" humanos; cultivo de una tradición naturalista presente en la Antigüedad y el Renacimiento, en la que confluyen de manera eclécrica, junto a motivos de la tradición aristotélica, otros de inspiración estoica y epicúrea. Dicha tradición marca los límites dentro de los cuales deben encontrar su explicación toda clase de fenómenos, reconduciendo a sus "causas naturales" las intervenciones milagrosas, y proporciona los fundamentos de una ética mundana, libre de mitos religiosos; opera en el fondo de la corriente libertina un claro relativismo escéptico que se configura como renuncia a la metafísica y a las visiones totalizantes, rechazo del dogmatismo y de las polémicas religiosas, valorización de un uso de la razón en el horizonte humano, limitado, provisional y siempre diverso según circunstancias de lugar y cultura; como característica general -que se presenta bajo diversos aspectos- se produce un alejamiento progresivo de lo sagrado, su exclusión de la historia, una reducción de los ritos y mitos religiosos a la esfera de comportamientos exteriores, prácticos y políticos" ${ }^{5}$.

Así considerado, el movimiento libertino, por su crítica de todo un sistema de valores que habían entrado a formar parte del patrimonio religioso cristiano del que habían recibido su esencial legitimación, por su concepción del hombre y del mundo, constituye un aspecto importante de la crisis de la conciencia europea, que, con frecuencia, no ha sido valorado suficientemente como consecuencia de una interpretación que privilegia en el campo de la historia de las ideas la racionalidad cartesiana o que, de la complejidad de corrientes y temas

5 T. Gregory, «Il libertinismo della prima metà del Seicento. Stato attuale degli studi e prospettive di ricercan, in Ricerche su letteratura libertina e lettertura clandestina nel Seicento, Atti del Convegno di studio di Genova, Firenze, 1981, p. 6. Traduc. nuestra. 
que constituyen la abigarrada filosofía del Renacimiento, no salva apenas sino aquellos motivos que se asocian a la corriente humanista o a los diversos capítulos de la revolución científica, haciendo un corte que resulta arbitrario entre erudicción y espíritu científico como algo inherente y definitorio del arranque de la mentalidad moderna. De ahí la conclusión de T. Gregory que subraya, en referencia a la obra famosa de P. Hazard: La crisis de la conciencia europea, como

«...muchos de los temas que él localiza en los últimos decenios del Diecisiete están ya presentes en la primera mitad del siglo. No se trata de ceder a la tentación de encontrar siempre en el pasado los gérmenes del futuro: pero cuando, por ejemplo, Hazard insiste sobre la importancia para la cultura europea de la experiencia de lo diferente, los descubrimientos geográficos, los viajes, las noticias de pueblos lejanos respecto a Europa, reencontramos una temática, que está en la cultura libertina, que en las relaciones sobre usos y costumbres de paises antiguos y nuevos — desde la China hasta América - veía una justificación de un relativismo radical que afecta al campo de las normas éticas civiles y religiosas hasta la negación de esa fe en la inmutabilidad y la universalidad de la naturaleza humana que había sido, según Meinecke, la estrella polar de la tradición occidental durante casi dos milenios" ${ }^{6}$.

Justo en la primera fase de la corriente libertina, lo que se ha llamado el "libertinismo radical», sofocado después por la reacción jesuítica en apoyo del establecimiento del absolutismo monárquico, hay que situar la figura original e inquietante de Giulio Cesare Vanini, cuyo proceso y muerte en la hoguera en Toulouse, en 1619, ("par cause d'athéisme») cuando el filósofo contaba sólo 34 años, constituye un episodio menos conocido pero no menos emblemático, entre el proceso de Giordano Bruno (1600) y el de Galileo (1633), en pleno furor contrarreformístico y aún reciente el recuerdo y frescas las secuelas de ese medio siglo de guerras de religión en Francia que se salda momentanemante con la conversión (1593) de Enrique de Navarra (Henri IV) al catolicismo y la promulgación del Edicto de Nantes (1598). Y, de 1618 a 1648, la Guerra de los Treinta años asolará y desgarrará el tejido de Europa en un conflicto de largo alcance que tendrá consecuencias decisivas para el futuro de las naciones europeas. Justo al comienzo de esta larga guerra, el año en que se produce la condena de Vanini, un filósofo de gran predicamento - también un

6 Cfr. T. Gregory, loc. cit., p. 25. Traduc. nuestra. 
burgués prudente- que participará en ellas (primero al lado de las tropas del Principe d'Orange, luego con las del Emperador) deslizará sobre las páginas de un diario íntimo su intención, en este siglo contrareformista y barroco, siglo del Teatro y de la Guerra de «avanzar enmascarado» ("larvatus prodeo»):

«De même que les comédiens lorsqu'on les appelle, pour qu'on ne voie pas leur timidité sur leur front, mettent un masque; de même moi, au moment de monter sur la scène du monde où je n'ai été jusqu'ici que spectacteur, je m'avance masquém?

La figura humana e intelectual de nuestro filósofo va cobrando su propio rostro y pérfil en la atmósfera ardiente de la Contrarreforma y del Barroco, rostro deformado por una leyenda surgida, aún vivas las ascuas y calientes las cenizas de su martirio, en su doble e irreconciliable versión de «héroe» o de "maldito".

El paciente trabajo de investigación en archivos jurídicos y en carpetas que guardaban celosamente la correspondencia diplomática de los poderes en liza de la época, ha ido permitiendo neutralizar esta leyenda en su aspecto más negro, o, en cualquier caso, relativizarla o reinterpretarla; verla con toda su carga sintomática de fobias u obsesiones propias de una época ensombrecida por rasgos especialmente duros.

Como ha escrito R. Villlari:

"Gli europei del XVII secolo ebbero anch'essi un'idea particolarmente drammatica del periodo in cui vissero et riuscirono a trasmetterla ai posteri: secolo di ferro, "mundus furiosus", età di tumulti e agitazioni, opressioni e intrighi, in cui "gli uomini divenuti lupi si mangiano l'uno con l'altro, età di disordine, di eversione, di rovesciamento della gerarchia, di velleitarismo; epoca di grandi tensioni, insomma, spesso considerate semplicemente negative anziché tappe necessarie per raggiungere un superiore equilibrio sociale e politico e una più profonda e comprensiva capacitá creativa” ${ }^{9}$.

7 Frase con la que comienza el Cahier de 1619 de R. DESCARTES, X, 213; cit. par G. RODIS-LEWIS, Descartes (Textes et debats), Paris, 1984, 7.

8 La publicación por E. NAMER, encargado de filosofía italiana en la Sorbona, de sus Documents sur la vie de Jules-César Vanini de Taurisano (199 p.) Bari,1965, y quince años después (Paris, 1980) de La vie et l'oeuvre de Jules-Cesar Vanini, Prince des libertins, mort à Toulouse sur le bûcher en 1619, marcó un hito importante en el sentido apuntado.

9 R. VILLARI, "Introducción», in L'Huomo Barocco, obra colectiva dirigida por R. VILLARI, Roma-Bari, 1994, p. ix. 
Nacido en 1585, en Taurisano (tierra de Otranto), entonces perteneciente al virreino de Nápoles, Vanini (su madre, Beatriz Lope de Noguera era miembro de la pequeña nobleza española y su padre un italiano, intendente del duque de Taurisano) realizó sus estudios de Doctor «in utroque iure» y los correspondientes de Filosofía y Teología en Nápoles, en una Orden como la del Carmen, que había elegido como mentor al «averroista» Jean de Baconthorp ("doctor resolutus"), al que Vanini llama —en relación con esos sus primeros años de formación - «preceptor meus» y del que Bruno Nardi ha escrito:

"...nessun theologo conosce e apprezza il comento de Averroè quanto lo conosce e l'apprezza il Baconthorp, il quale si compiace citarlo persino trattando dei più ardi misteri della fede, e di prenderne espesso le difese, contro le storture che gli avversari facevano del pensiero dell'arabo" ${ }^{10}$.

Esta misma impronta averroísta y su interés, muy temprano, por las cuestiones de filosofía natural le habrían impulsado a ampliar estudios en la universidad de Padua, que disfrutaba de un mayor ambiente de libertad al amparo de un poder, celoso de su independencia frente al poder de Roma, como era el de la Serenísima; y donde la enseñanza de las obras de Aristóteles se veía bien representada por el magisterio, esencialmente incómodo para la ortodoxia católica de un personaje como Cremonini, al que una leyenda anacrónica e imparcial ha querido identificar simplemente con el filósofo retardatario que no quiso mirar por el telescopio de Galileo ${ }^{11}$. Los años pasados en PaduaVenecia tuvieron que aportar experiencias decisivas al joven filósofo, que habría puesto sus dotes de controversista al servicio de la independencia de la República de Venecia -tras la situación creada a raiz del Interdetto- en la polémica con Belarmino que lideraba el gran Paolo Sarpi, como teólogo de la Serenísima y alentador de un movimiento de acercamiento con el mundo protestante (el «latitudinarismo»), a la búsqueda de un consensus sobre la base de elementos doctrinales comunes de la tradición en un espíritu de tolerancia y de mayor independencia respecto a las pretensiones de Roma ${ }^{12}$.

10 B. NARDI, Sigieri di Brabante nel pensiero del Rinascimento, Roma, 1945, pp. 105-114; cit. par A. CORSANO, "Vanini e Baconthorp", Giornale Critico della Filosofia Italiana, XIX, 1970 , pp. 340-341, XIX, 1970, pp. 340-341.

11 A este respecto sigue siendo interesante consultar la obra de L. MABILLEAU, Étude historique sur la philosophie de la Renaissance en Italie. Cesare Cremoni, París, 1881.

12 Cfr. F. DE PAOLA, Vanini e il primo ' 600 anglo-veneto. Ricerca su alcuni personaggi e movimenti politici, religiosi e filosofici e sugli anni anglo-veneti di $G$. C. Vanini ricostruiti con l'ausilio di documenti inediti e non, Cutrofiano, 1979. 
En estos momentos Venecia y su Universidad aparecen como un escenario privilegiado donde se asiste a un cruce violento de tendencias sobre un fondo de crisis profunda en el campo de las relaciones de poder, de la lucha religiosa Reforma-Contrarreforma, y del que no será un capítulo nada despreciable la gestación del cambio de "paradigma" en la revolución científica que, bajo la inspiración de Copérnico, están protagonizando Kepler y Galileo.

Fué usando los buenos oficios del embajador inglés Carleton como Vanini (que - siendo aún bastante joven: no tiene más de 27 años- se hace admirar por su agudeza de ingenio y capacidades controversísticas) llega a Inglaterra y es acogido por el Arzobispo de Canterbury, como un "exiliado" procedente del campo católico. Su conversión a la Iglesia Anglicana (recordemos que Bruno - con el que se le ha asociado demasiado facílmente pero con el que seguro compartía su desprecio por las iglesias- se había hecho calvinista en Ginebra y protestante en Wittenberg para acabar volviendo fatalmente al campo católico) se produce enseguida y esto en presencia del autor del Novum Organum, Sir Francis Bacon de Verulamio. La corta experiencia inglesa (1612-1614) se saldará, sin embargo, con un doble proceso: eclesiástico y civil como consecuencia del trabajo detectivesco de los espias de su protector, el Arzobispo de Cantorbery - convertido ahora en su perseguidor- que, entre otros cargos, le acusan de haber encontrado, entre sus libros, obras en italiano del Aretino y de Maquiavelo. Una trama rocambolesca en la que participan los servicios de la embajada española ${ }^{13}$ permite a Vanini escapar de prisión y abandonar el campo protestante, haciendo su entrada de nuevo en la Iglesia Católica, en presencia del Nuncio en Bruselas, Bentivoglio, —que había sido díscipulo de Galileo en Padua-, eso sí, rebajado de algunas obligaciones propias de su estatus de miembro de la orden carmelitana.

El paso por París incluye el encuentro con el influyente Nuncio Ubaldini, del que solicita permiso para consultar en la rica biblioteca de la Nunciatura los libros prohibidos, so pretexto de escribir una obra sobre el Concilio de Trento, centro de los debates de la época entre católicos y protestantes. Ubaldini trasmite esta petición de publicación al Santo Oficio, sin apoyarla,

13 Cfr. E. Namer, Documents sur la vie de Jules César Vanini de Taurisano, Bari, s. d. (1965): carta del cardenal Millino a Don Alonso de Velasco, embajador de España en Londres del 10 de septiembre de 1613 (pp. 94-95) y otra del mismo cardenal a Don Diego de Sarmiento de Acuña, nuevo embajador español del 22 de marzo de 1614 (pp. 96-97), las dos encontradas por G. Spini en los archivos de Simancas. 
sugiriendo, por el contrario, que se ordene al filósofo dirigirse a Italia, ya que:

«[...] per omni caso, che puo avvenire, meglio è che simil sorte di persone se ritirino quanto prima in quella parti, ove si vive con più di timore di Dio, e con meno di libertà, di quel che si fa quì ${ }^{14}$.

Vanini no tiene prisa por llegar a Roma. Su paso por Génova donde es acogido como preceptor privado por la familia de Scipion Doria, miembro de la aristocracia local, le confirma su desconfianza de lo que podía aguardarle allí, al enterarse de como la Inquisición está tras la pista de su compañero de infortunio, el también carmen Ginochio.

La apresurada vuelta a Lyon en estas circunstancias nos da el contexto de la publicación (junio de 1615) de una de las obras que conservamos del filósofo, con el curioso título de Amphitheatrum aeternae providentiae, divino-magicum, christiano-physicum, necnon astrologo-catholicum adversus veteros philosophos, atheos, epicureos, peripateticos et stoicos. Aunque el libro sale con todos los requisitos y aprobaciones de la censura, Vanini juzga, sin embargo, necesario poner su publicación bajo la alta protección de D. Francisco de Castro, embajador en ese momento del Rey de España ante la Santa Sede y antiguo protector de su familia, y esto para evitar - como se puede leer en la dedicatoria - "las venenosas mordeduras de hombres corrompidos» ${ }^{15}$.

Una carta del Nuncio Ubaldini nos habla de la presencia de Vanini en París, dos meses después de la publicación del Amphitheatrum. Vanini será recibido por la puerta grande en los medios influyentes de la corte del Louvre "precedé d'une reputation de bel esprit et soutenu par le plus célèbre poète du temps» ${ }^{16}$. Se trata de otro italiano, el poeta Gian Battista Marino, a quien Vanini había conocido probablemente en Génova y al que se honraban en proteger como mecenas, y de que le dedicara sus poemas, los grandes de la Corte; sobre todo el muy poderoso Concini, favorito de la también italiana Maria de

14 Cfr. F. P. RAIMONDI, "Documenti vaniniani nell'Archivio Segreto Vaticano", Bolletino di Storia della filosofia dell'Università degli Studi di Lecce, VIII, 1980-1985, p. 196. Y NAMER, Documents, op. cit., p. 189.

15 Cfr. Giulio Cesare Vanini, Opere, edición de G. Papuli et F. P. Raimondi, Galatina, 1990 , Dedicatoria, n. n. 12.

16 E. Namer, La vie et l'oeuvre de Jules César Vanini, Prince des Libertins, mort à Toulouse sur le bûcher en 1619, Paris, 1980, p. 143. 
Médecis, regente durante la minoría de edad de Luis XIII. En este mundo, tan bien descrito por Pintard en su obra ya clásica sobre el llamado «libertinaje erudito" del XVII, se hace valer Vanini que se convertirá en un filósofo «à la mode" en ese ambiente cortesano que le admira y en el que figuran personajes como M. Arthur d'Epinay de Saint-Luc, cuñado del baron de Basompierre, el otro personaje importante con el favorito Concini en el entorno de Maria de Médicis, pero tambien Nicolas Brûlart, marques de Sillery y Adrian de Montcluc, conde de Cramail o Caraman, o Henri II, duque de Montmorency, Gobernador del Languedoc y protector de Théophile de Viau, que, años después, será procesado y acusado de ser discípulo del filósofo.

En septiembre de 1616 aparece con todas las garantías oficiales, y tras haber pasado la censura de dos doctores en Teología de la Sorbona: E. Corradin y C. le Petit, una segunda obra de Vanini en forma de diálogos: se trata del De Admirandis Naturae Reginae, deaeque mortalium arcanis, bajo la protección esta vez del muy influyente Barón de Bassonpierre a quien el autor dedica la obra.

Sólo un mes después, la nueva obra de Vanini es condenada por la Sorbona, alegando que el manuscrito presentado a los censores no correspondía con el libro publicado, versión que sin embargo no puede sostenerse en ninguna base documental; más bien parece que, dado el éxito de los Diálogos en los ambientes libertinos de la Corte del Louvre - algo en lo que sí coinciden los testimonios de la época- los censores revisaron su juicio, al socaire también de un cambio de circunstancias políticas que afectaba a los protectores de Vanini. El hecho es que el filósofo, al ver desaprobada y condenada su obra - la costumbre era retirar el libro prohibido de las librerías, quemarlo en la Place de Grève y entablar un proceso a su autor- huye y se aleja de París, probablemente bien aconsejado por sus protectores.

Vanini pudo llegar a Toulouse, esta vez con el falso nombre de Pompeo Ugilio, a finales de 1617 , después de un período en el que se le ha podido ver en algún otro lugar de Francia, ejerciendo de «médico empírico». La elección de Toulouse, centro en estos momentos del integrismo religioso en la lucha contra la herejía protestante, puede entenderse justamente porque sería el lugar más descartable por los que estaban implicados en su persecución, contando además con la dificultad de transpasar - lo que seguramente pudo hacer con la ayuda del Conde de Caraman, su nuevo protector- las puertas que guardaban celosamente la ciudad «santa». Eso sin contar con el hecho de que 
la estrategia por así decirlo de camuflaje -explicable por las difíciles condiciones de la época- se vió acompañada casi siempre en el caso de nuestro filósofo por una actitud de arrojo y gusto por la provocación cuando no de evidente aunque calculada osadía.

La buena acogida de las palabras y los gestos del filósofo entre la juventud acomodada, asociada a los ambientes libertinos de Toulouse, viene documentada por los testimonios de la época:

«... le bruit de son sçavoir s'espandit incontinent par toute cette ville renommée; bien qu'il n'y avoit fils de bonne mere, que ne desirast de le cognoistre" ${ }^{17}$.

«....et nos jeunes gens d'amirer le novateur...ils admiraient tout ce qu'il disait, l'imitaient, s'attachaient à lui...." ${ }^{18}$.

Vanini, después de haber llevado una vida más bien discreta, -haciéndose pasar por un médico empírico probablemente llegado de España; su madre era española y el castellano con seguridad una de sus lenguas- habría comenzado a desplegar sus talentos de controversista en este medio tan suspicaz e intolerante para las nuevas ideas, sin duda empujado por lo que era su vocación más profunda: «destilar para la juventud de este siglo algunas gotas de una filosofía menos conocida... atraverse a hacer algo por los amigos y por la filosofia) ${ }^{19}$.

El 2 de agosto de 1618 se produce la orden de arresto del filósofo:

«Le jeudi, second jour du mois d'aoust, sur l'advis qui fut donné aux dits sieurs capitouls, fut prins dans la maison des héritiers de feu Monhalles au capitulat de Daurade, et fait prisonnier par les sieurs d'Olivier et Virazel capitouls et conduit à la maison de ville, un jeune homme soy-dixant agé de trente-quatre ans, natif de Naples en Italie, se faisant nozmmer Pomponio Usciglio, accusé d'enseigner l'atheisme, duquel ils etoient en queste depuis plus d'un mois. On disoit qu'il estoit venu en France à desseing de tenir cette abominable doctrine. C'estoit un homme d'assez bonne façon, un peu

17 Fr. DE ROSSET, Les histoires mémorables et tragiques, París, 1619, p. 196-7.

18 G. B. DE GRAmOND, Historiarum Galiae ab excesu Henrici IV liibri XVIII, Tolosae, p. 208.

19 Cfr. Giulio Cesare Vanini, Opere, edic. de G. Papuli y F. P. Raimondi, Galatina, 1990, De Admirandis, 3,4. 
maigre, le poil chastaing, le nez long et courbé, les yeux brillants et aucunement agars, grande taille. Quant à l'esprit il vouloit paroistre savant en la philosophie et médicine qu'estoit l'office qu'il se disoit professer. Il faisoit le theologien, mais meschant et detestable s'il en fut oncques: il parloit bien latin, et avec une grande facilité [...]” ${ }^{20}$.

Una vez en prision, empezará un largo proceso que acabará seis meses más tarde con el suplicio y la muerte del filósofo.

El 9 de febrero de 1619, el Parlamento de Toulouse pronunciará la condena a muerte, declarando a Vanini

«[...] ataint et convaincu des crimes d'ateisme, blasphèmes, impiétés et autres crimes $[\ldots]$ "

condenándole a

"[...] estre délivré es mains de l'exécuter de la haulte justicie, lequel le traynera sur une claye en chemise ayant le hard au col et portant sur ses epaules ung cartel contenant cez motz: 'Atéiste et blasphemateur du nom de Dieu' [...] et après l'admenera en la place de Salim et attachera à ung poteau que y sera planté, luy coupera la langue et l'estranglera et après sera son corps bruslé au bucher que y sera apresté et ses cendres jettées au vent» ${ }^{21}$.

Vanini que, según los testimonios mas creibles de la época, adoptó una actitud serena y valiente ante la muerte ( Andiamo, andiamo a morire da filosofor fueron sus palabras al recibir la condena), fué quemado en la Plaza de Salin y sus cenizas arrojadas al viento el mismo día ( 9 de febrero de 1619) en que se produjo y ejecutó su condena a muerte.

El 16 de julio de 1620, el Tribunal de la Inquisición de Toulouse, tras haber sabido que Pompeo Ugilio et Giulio Cesare Vanini eran una y la misma persona, sometió los libros del filósofo —que habían sido publicados siguiendo todas las normas al uso- a una nueva censura y los condenó en una especie de segundo proceso, obra esta vez de la autoridad religiosa:

"Tanquam veri Dei cultui et agnitione contrarios, atheismi tanto periculsiores assertores quanto occultiores et libertatis abominandae vindices» ${ }^{22}$.

20 Cfr. Annales Manuscrits de l'Hotel de Ville de Toulouse, in NAMER, Documents, op. cit., p. 115.

21 Ibidem, p. 113-114.

2 lbidem, p. 132. 
Los libros de Vanini fueron incluidos en el Indice de libros prohibidos. En un Indice español del s. XVII podemos leer:

"Julius Caesar Vaninus, qui vulgo Lucilius vocabatur, patria Naepolitanus, impiisimus Atheus. Denique impius virus traditus est flammis Tolosae, an. 1619. Eiusque omnia perpetuo damnata» 23 .

Esta condena que pretendía ser perpetua marca, justo poco tiempo después del proceso de Toulouse, la línea que separa la muerte del hombre y del filósofo y el nacimiento del mito; mito bifronte de héroe y de maldito, que explica la insistente referencia a Vanini, convertido en símbolo de una figura de la conciencia: el criptoateismo que aparece ya en la acusación del rector de Utrecht ("Vaninus — proclamaba Voetius- inter eruditus atheos aquila") a Descartes, acusándole de ser «alter Vaninus», o en la referencia a Lucilio (corrupción de Ugilio, anagrama a su vez, tal vez de Giulio, en la versión clandestina del nombre del filosófo), como sinónimo de incrédulo (así, p. e., en Los caracteres de La Bruyère, capítulo Des esprits forts, se puede leer. "avouez-le Lucile, vous douterez alors qu'il y ait eu un César» ${ }^{24}$; pero también de la conciencia resistente y heroica frente a la impostura religiosa como aparece en el poema «Vanini» que Hölderlin dedicará al filósofo:

Den Gottverächter shalten sie dich? mit Fluch

Beschwerten sie dein Herz dir und banden dich

Und übergaben dich den Flammen,

Heiliger Mann! o warum nicht kamst du

Vom Himmel her in Flammen zurück, das Haupt

Der Lästerer zu treffen und riefst den Sturm,

Das er di Asche der Barbaren

Fort aus der Erd', aus der Heimat werfe!

Doch die lebend libtest, die dich empfing,

Den Sterbenden, die heil'ge Natur vergisst

23 Index librorum probibitorum [...] A. Sotomaior, Madrid, 1667, p. 675; cit. por A. NovickI, "Le categorie centrali della filosofia del Vanini», in Le interpretationi de G. C. Vanini, dir. por G. Papuli, op. cit. p. 170.

24 Cfr. LA BruYère, Les caractères, précédés des Caractères de Théophraste, GarnierFlammarion, Paris, 1965, p. 393. 
Der Menschen Tun und deine Feinde

Kehrten, wie du, in den alten Frieden.

(HÓLDERLIN, Poemas de la madurez, 1798-1800) 25

Nota.-La revista Kairos, revista de la Facultad de Filosofia de la Universidad de Toulouse-Le Mirail (Presses Universitaires du Mirail, 1998) dedica su último número (n. ${ }^{\circ}$ 12, Junio-1998) monográficamente a Vanini. Bajo el título: G. C. Vanini (1585-1619) Libertinage et philosophie à l'Époque moderne, se pueden consultar una serie de trabajos de diversos especialistas que dan cuenta de un interés reciente (que renueva el interés de los años 60, a iniciativa de investigadores como A. Corsano en Italia, E. Namer en Francia o A. Nowicki en Polonia) por el personaje y la obra del filósofo italiano. El número incluye una bibliografía distribuida en dos epígrafes: I.-Obras de Vanini: ediciones originales, ediciones críticas del texto latino, traducciones (se menciona entre otras una traducción reciente al italiano con abundante aparato crítico a cargo de $\mathrm{F}$. P. Raimondi y L. Grudo, y un proyecto de edición crítica bilingüe latín-francés como parte del programa de publicación de la serie "Libre pensée et litterature clandestine» de la editorial Universitas, serie realizada en colaboración con la Voltaire Foundation de Oxford, dirigida por A. McKenna) y II.-Principales publicaciones sobre Vanini a partir de los años 60 hasta nuestros días (16 páginas).

25 Cfr. a propósito, F. Politr, Il Vanini di Hölderlin, Quaderni del Dipartimento di Lingue e Letterature Straniere della Facoltà di Magistero di Lecce, X. 1988, pp. 265- 281. 